\title{
Emerald Advances in Autism
}

\section{ASD and Hate Crime}

\begin{tabular}{|r|l|}
\hline Journal: & Advances in Autism \\
\hline Manuscript ID & AIA-08-2017-0015.R1 \\
\hline Manuscript Type: & Review Paper \\
\hline Keywords: & Autism Spectrum Disorder, Hate crime, Criminal Justice System, Victim \\
\hline \multicolumn{2}{|c}{} \\
\hline
\end{tabular}

SCHOLARONE $^{\text {m }}$

Manuscripts 


\section{Hate Crime \& Flagging}

- Has any person, regardless of whether or not this is the victim, perceived this as a hate crime? If yes - has it been flagged as a hate incident (where the conduct does not amount to a criminal offence) or a hate crime?

- Consider the evidence which makes this a hate crime-this will involve analysis of hostility, motivation and vulnerability.

(a) "that, at the time of committing the offence, or immediately before or after doing so, the offender demonstrated towards the victim of the offence hostility based on a disability (or presumed disability) of the victim".

(b) "that the offence is motivated (wholly or partly) by hostility towards persons who have a disability or a particular disability."

- Has the interview dealt with identification of hostility?

- Has the case been flagged as involving a vulnerable victim?

- Does the case fall within any other hate crime categories, for example domestic abuse; homophobic; transphobic; racial or religious?

- Does the perpetrator have Autism and, if so, should alternative disposal be considered?

Fig 1: Autism: Checklist for Prosecutors Version 1.0 


\section{Hate crime against people with Autism Spectrum Disorders}

\section{Introduction}

It is estimated $15 \%$ of adults worldwide have a disability (Hughes et al, 2012), with Autism Spectrum Disorders (ASD), affecting an estimated $1.1 \%$ of the adult population in England (Brugha et al, 2012). This article offers a perspective from the United Kingdom (UK), where there is significant legislation in place relating to ASD and other disabilities that are aimed age equality, inclusion and protection of rights as citizens.

The definition of Hate Crime differs across the UK. In England and Wales hate crimes are defined as 'any hate incident, which constitutes a criminal offence, perceived by the victim or any other person, as being motivated by hostility or prejudice'. Whilst in Scotland it is: 'crime motivated by malice or ill will towards a social group.' In Northern Ireland, although there is no definition of hate crime in law, this type of offence is still recorded by the Police. Hate crimes or incidents are motivated or thought to be motivated by prejudice and hostility towards a person's disability, race, religion, transgender identity or sexual orientation. It is these five strands that identify Hate Crimes. In Northern Ireland and Scotland, in some cases sectarianism is also included as a Hate Crime (Amnesty International, 2016).

The understanding of the concept of 'hate crimes' and how they are perceived by individuals has meant that there is, as such, no real consensus as to the key characteristics. One school of thought is that hate is secondary as a motive, with the primary motivation as seeing the individual as different (Gerstenfeld, 2004). Whoever the target of hate crimes the definition published within the Stephen Lawrence Inquiry ${ }^{1}$ (Mac Pherson Report 1999) is

\footnotetext{
${ }^{1}{ }^{1}$ The Stephen Lawrence Inquiry ' conducted by Sir William Macpherson followed the racially motivated murder of Stephen Lawrence, and reported the original Metropolitan Police Service investigation had been incompetent with fundamental errors, e.g. failing to give first aid, failing to follow obvious leads or to arrest suspects. The report found the force to be institutionally racist. https://www.gov.uk/government/uploads/system/uploads/attachment data/file/277111/4262.pdf
} 
often seen as the benchmark and can be applied to other areas, i.e. 'any crime, which is perceived to be racist by the victim or any other person'. So, for individuals with ASD Hate Crimes are any crime which targets them because they have an ASD or that the person perceives the crime has been committed against them because they have an ASD.

Hate crimes cover a range of offences that are threatening or harmful to the person including verbal abuse, harassment, bullying or intimidation, physical attacks, threats of violence, abusive phone or messages or hate mail, online abuse via social media, posting of discriminatory literature or posters, criminal damage to property such as graffiti or arson and malicious complaints. Globally, about half a million adults die every year because of interpersonal violence (Hughes et al. 2012). Hate crimes may be directed at individuals or the group they are a part of, or identify with. Hate crimes aimed at an individual not only affect that person but can also function to bring terror to all who are in that group and serve to compromise its wellbeing and security (Perry 2001). Therefore, the emotional and psychological impact hate crime, even attacks on individuals are seen as hurtful to both the victim and the group they are seen to be a part of (Iganski, 2008).

\section{Hate crime and People with ASD}

In the UK, a substantial proportion of people with ASD live either in the family home, or with support in their own home or a residential service. How much contact people have with their community and the support to access their community safely often depends on where they live and their level of ability (Emerson and Hatton, 2008). Adults with ASD have persisting negative effects on learning and development of independence in adulthood (Howlin et al. 2004). In 2007, the yearly cost to society of each adult with ASD in the UK was estimated to be $£ 90,000$ (Knapp et al. 2007). It is recognised that significant numbers of adults with ASD are more vulnerable to co-existing conditions such as intellectual disability (ID). Those adults with more severe presentations of ASD or who have severe ID are more likely to be recognised and supported so may be less at risk of being a victim of Hate Crimes. 
Those with higher levels of functioning tend to be overlooked in the community and are less likely to receive or seek the necessary support from social and local authority services (Gravell, 2012). (National Audit Office, 2009). This lack of engagement makes them more vulnerable to victimisation (Archer \& Hurley, 2013).

The evidence as to how hate crime, affects people with ASD is limited and most of the data available on this offence is related to overall disability discrimination (Hughes et al. 2012). Given the overlap and scarcity of studies on hate crime that are ASD specific, literature into hate crimes against people with ID is a valuable source, with rates of $31 \%$ of adults with mild or severe ID living in communal care establishments having ASD (Brugha et al, 2012). In 2004, the National Learning Disability Survey for England found that $43 \%$ of people with ID had reported being bullied at school, 32\% did not feel safe in their home or community; $9 \%$ had been a victim of crime, and $2.8 \%$ had been assaulted, which is above the population average. Those with lower support needs were more likely to be the victims of crime and bullying. Additionally, within the ID population, those who were younger and those from a lower socio-economic background were also found to be more vulnerable to crime and bullying. Furthermore, rising numbers of media reports emphasise cases of physical violence, sexual abuse, and hate crime inflicted on individuals with ID and ASD in homes, institutions, communities, and other settings (Quarmby, 2011; BBC news reports 2009, 2011, 2014; Krug et al. 2002; Guardian news report, 2011). However, whether this increase indicates a rising prevalence of violence against individuals with disabilities, more consistent reporting to authorities or greater media coverage than historical coverage previously, is unclear as stated previously.

In general people with disabilities seem to be at an increased risk of interpersonal violence (Hughes et al. 2012; Quarmby, 2011) because of several factors: exclusion from education and employment, the need for personal assistance with daily living, reduced physical and emotional defences, communication barriers that hamper the reporting of violence, societal stigma, and discrimination (Quarmby, 2011; Nosek et al. 2001, Saxton et al. 2001; BeadleBrown et al. 2014). The Equality and Human Rights Commission (EHRC) research (2009) into 
the safety and security of disabled people reported that violence and hostility is a daily experience for some people with disabilities. The nature of victimisation is varying, however, the report found that it is persistent and re-occurring.

As mentioned earlier the evidence on ASD and hate crime is limited and it is only since 2012, has there been a concentrated interest in autism 'hate crime'; this is partly in response to legislative pressure as a result of the Autism Act 2009, the first disability specific legislation in the UK. This has coincided over the last decade, with an increasing interest in disability hate crime and victimisation in generaL (EHRC, 2009; British Crime Survey, 2013). Although the term 'hate crime' is part of common language; awareness of it has not translated into better understanding or reforms within the public sector (Roustone et al. 2011; EHRC, 2009; Hemmings et al. 2013; Department of Health, 2010; Garland, 2012). With the introduction of the Autism Act 2009 and Autism Strategy 2010, there has been a momentum to provide better provisions for adults with autism; and although an increasing amount of research has been done to quantify violence against individuals with disabilities, there is a significant gap in the literature with regards to autism hate crime or victimisation (Beadle-Brown et al. 2014; Archer \& Hurley, 2013; Garland, 2012; King \& Murphy, 2014). Study methods and the definitions of autism, victimisation and violence vary widely, and the literature is inconclusive on quantitative syntheses of hate crime relating to autism. Often in studies ASD is poorly defined, for example, ID has been used interchangeably with autism (Beadle-Brown et al. 2014; Hughes et al. 2012).

\section{Hate Crime and ASD}

\section{Bullying}

A survey from the National Autistic Society (2013) reported that more than half of people with ASD including Asperger syndrome they spoke to had been bullied or harassed as adults, and furthermore let down by the criminal justice system. Fisher et al (2010) compared adults without disabilities to individuals with ID, who were more likely to experience social victimization, related to money/theft, teasing/persuasion, and abuse. Their narrative results 
and findings indicated that although individuals who were higher functioning were more aware of vulnerable situations, they still experienced victimisation at rates similar to those less able to detect risk (Risk ratio - 1:5).

\section{Victims of sex crimes}

Brown-Lavoie et al. (2014) explicitly explored the risk of sexual victimization in individuals with ASD and what increased that risk. They compared ninety-five adults with ASD and 117 adults without ASD through questionnaires regarding sexual knowledge sources, actual knowledge, perceived knowledge, and sexual victimization. Individuals with ASD obtained less of their sexual knowledge from social sources, more sexual knowledge from non-social sources, had less perceived and actual knowledge, and experienced more sexual victimization than controls. The increased risk of victimization by individuals with ASD was partially mediated by their actual knowledge. Individuals with ASD were between two and three times more likely to experience sexual contact victimization, sexual coercion victimization, and rape than comparison group. Regardless of sex, both male and female individuals with ASD were more likely to be sexually victimised. This is the first study to use self-report to ask adults with ASD about their actual and perceived sexual knowledge and experiences of victimisation. With the link between knowledge and victimization having important clinical implications for interventions.

\section{Responses to ASD hate crime}

The countries in the UK have their own prosecuting bodies, so procedures may differ. In Scotland it is the Crown Office and Procurator Fiscal Service (COPFS), whereas in England and Wales it is The Crown Prosecution Service (CPS). The function though is similar, which is to follow strict criteria to establish whether there is enough evidence to pursue a prosecution and whether it is in the public interest to proceed. The CPS is given as an example in Figure 1.

INSERT FIGURE 1 AROUND HERE 
Many police services have publicly acknowledged that previously they have neglected the problem of disability hate crimes and have failed to give it the same status and attention as they have to racial, religious, or homophobic hate crimes (Gravell, 2012). The research and campaigning work of charitable organisations such as the National Autistic Society and MENCAP, has greatly helped to bring attention to the issues of hate Crime relating to ASD and ID in the public domain. One example is that hate crimes has been a topic and key focus of discussions by the All Party Parliamentary Group (AAAPG) on Autism. APPGs are informal, cross-party, interest groups of Members of Parliament and Peers i.e. those interested in a particular issue, including civil servants, advocates, carers and most importantly individuals

with autism, for 2014. There are also other organisations who provide support and continue to raise awareness for the needs of those subject to hate crimes, such as the National Police Autism Association who have developed a network of champions to provide local support in to police Forces raising awareness and helping with discussion of personal, work and service delivery issues. This type of support is crucial in promoting awareness given the fact often people with Autism may go unidentified whilst at the police station. In terms of helping someone to report crime there are resources such as the True Vision webpage http://report-it.org.uk/home which explains about hate crime and how to get support and report it. Some police forces will now also offer cards which have numbers for victims to report hate crime, or to give in at the police station to inform the police they have autism, one such scheme is operated by Bedfordshire Police. To support individuals, it is necessary to have a variety of effective reporting mechanisms to ensure that any disabilities are identified, including hidden impairments, or 'hidden disabilities', such as, 'autism' and 'learning disability'. Victims must then be supported sufficiently, their evidence given in the most effective manner and kept fully informed of what is happening in their case. This is the idealised version of how disability hate crime should be dealt with. (Challenge it, Report it, Stop it, 2012).

Change has come about, mainly due to concerns that have been raised in relation to how the police have dealt with disability hate crime in recent years because of this interest. Whilst there is an acknowledgment that progress has been made in relation to certain hate crimes, there is a lack of confidence that society's attitudes towards those with disabilities 
has progressed at the same pace (Gerstenfeld, 2004; Garland 2012). It is the case it is often tragedy that can create the greatest awareness and acts as a catalyst for change. Fiona Pilkington, killed herself and her severely disabled daughter in 2007 after years of harassment and intimidation. The family had complained to police about the abuse on 27 separate occasions between 2004 and 2007, and twice petitioned their local MP on two separate occasions. The Independent Police Complaints Commission (IPCC), which investigates police complaints, published its review into the Pilkington case in May 2011. The investigation concluded that among the failings of the police was not identifying the family as vulnerable, which meant police did not provide a structured, cohesive response to the prolonged antisocial behaviour they endured.

Although this may have changed opinion and helped bring about changes in the way we support and treat victims hate crimes, societal change still needs to be worked on. A recent newspaper article on the area where the Fiona Pilkington tragedy occurred suggests little has changed for residents locally with incidents of abuse common place. http://www.independent.co.uk/news/long reads/fiona-pilkington-frankie-pilkingtonsuicide-learning-disabilities-bullying-hate-crime-a8004526.html

\section{Discussion}

Even though progress has been made in the UK there is still a need to create further awareness of what disability hate crime is, its scope and its victims. Increasing the reporting of disability hate crime has always been difficult for a number of reasons, such as lack of support, not knowing the process or just through fear. Processes to manage disability hate crime need to be embedded within the routine working practices of the police and CPS who should work together to enhance how to identify and progress these cases. (Gravell, 2012). The Joint Disability Hate Crime Review (Brereton, 2013) came about following a culmination of pressure from the public as well as other bodies with regards to tackling the issues of victimisation. The review recommends that together with the Challenge it, Report it, Stop it report (HM Government, 2012) there is sufficient scope given recent progerias to "provide a unique opportunity for the police, CPS and probation trusts to implement changes to policies and procedures. Practices need to be changed to work towards improved outcomes 
for victims and contribute to changing society's attitudes." In April 2005 section 146 of the Criminal Justice Act 2003 (s.146 CJA 2003) was introduced which created the 'sentencing provision' relating to the punishments for perpetrators of disability hate crime. There is still argument that disability hate crime requires additional status given that social attitudes are still ill informed (Gravell, 2012; Beadle-Brown et al. 2014; King \& Murphy, 2014). There is still a lack of clarity and understanding as to what constitutes a disability hate crime and confusion between policy definitions and statutory sentencing. Currently the court can regard the defendant's behaviour as an aggravating feature if (a) the offender has demonstrated hostility based on a disability or (b) the offence was motivated by hostility towards persons who have a disability. This causes difficulties not only for practitioners in the identification and recording of disability hate crime but also for members of the public, including victims who are disabled (Joint Disability Hate Crime Review, 2013; Brereton, 2013). A clear recommendation from public reports is that, improvements need to be made by the police and CPS in how they identify and record disability hate crime. All police, CPS and probation staff need to be fully aware of the statutory provision in and there needs to be a common policy definition that is universally recognised and applied at 'ground level', which is simple to interpret. This has been outlined very concisely in the Joint Disability Hate Crime Review, 2013. The under reporting of disability hate crime remains a significant concern and needs to be addressed (NAS Hate Crime Survey, 2013; Brereton, 2013). It is still the case victims are not empowered or getting the support and help to report disability related hate crimes. This means is that those being targeted and most vulnerable are not able to reach out for adequate support which in turn perpetuates their situation further and threatens both their mental health and general wellbeing and negative impact on their quality of life. There is also evidence to suggest that those with ASD and ID in these situations will be more likely to present in forensic and clinical settings (King and Murphy, 2014).

A key recommendation from the Joint Commissioned report (2013) is that the CPS needs to improve its performance in relation to the quality of case preparation to ensure that disability hate crimes are effectively prosecuted. For this to happen there needs to be greater awareness of autism throughout the Criminal Justice System (CJS). This follows the admission that people can feel uncomfortable around and about disability and have widely 
varying levels of experience of interaction with disabled people (EHRC 2013). This may go some way to addressing the low levels of reporting that exists. It is these attitudes and current experiences that need to be challenged to ensure disability hate crimes are treated on an equal footing to the other strands of hate crime such of race, religion, sexual orientation or transgender identity and remember that many people with ASD will also belong to one or more of the other groups at risk of hate crime.

\section{Conclusion}

In summation, the current academic literature is not very clear with regards to how it defines hate crime or victimisation for adults with ASD and ID. It is crucial to take in to account the experiences of this vulnerable population, as public policy currently is reflecting that there is a need for further provisions and support for these victims. The CJS, police and probation want to tackle this; however, the academic literature is sparse in its understanding of the issues. The literature is mostly on the experiences of children and adolescents. Clearly, reports in the public domain are arguing that adults with ASD are being targeted. Therefore, it would be useful to map what understanding is present in the current academic literature on adults with ASD and does it reflect the discussion above.

Additionally, it would be useful to see where the gaps are to inform future research. 


\section{REFERENCES}

Amnesty International (2016) Tackling Hate Crime in the UK

Archer, N., \& Hurley, E. A. (2013). A justice system failing the autistic community. Journal of Intellectual Disabilities and Offending Behaviour, 4(1/2), 7-7.

Beadle-Brown, J., Richardson, L., Guest, C., Malovic, A., Bradshaw, J and Himmerich, J. (2014). Living in Fear: Better Outcomes for people with learning disabilities and autism. Main research report. Canterbury: Tizard Centre, University of Kent.

BBC News (January 23, 2009) Dementia relatives admit abuse.

http://news.bbc.co.uk/1/hi/health/7842549.stm

BBC News (June 20, 2011). Police 'fail' disabled people suffering hate crime. http://www.bbc.co.uk/news/uk-13836337

BBC News (October 7, 2014). Bijan Ebrahimi murder: IPCC report complete. http://www.bbc.co.uk/news/uk-england-bristol-29521557

Brereton, S. (2013). Living in a Different World: Joint Review of Disability Hate Crime. Probation Journal, 60(3), 345-346.

British Crime Survey, 2013

Brugha T, Cooper S.A., McManus S., Spiers, N. and Tyrer, F. (2012) Estimating the Prevalence of Autism Spectrum Conditions in Adults: Extending the 2007 Adult Psychiatric Morbidity Survey. London: NHS, The Health and Social Care Information Centre.

Department of Health. (2010). Fulfilling and rewarding lives, the strategy for adults with Autism in England. London: Department of Health.

Equality and Human Rights Commission (2009). Disabled people's experiences of targeted violence and hostility. Manchester, $\mathrm{NH}$.

Fisher, M. H., Moskowitz, A. L., \& Hodapp, R. M. (2012). Vulnerability and experiences related to social victimization among individuals with intellectual and developmental disabilities. Journal of mental health research in intellectual disabilities, 5(1), 32-48. 
Garland, J. (2012). Difficulties in defining hate crime victimization. International review of victimology, 18(1), 25-37.

Gerstenfeld, P.B. (2004). Hate Crimes: Causes, Controls and Controversies. Sage; London.

Gravell, C. (2012). Loneliness and Cruelty: People with Learning Disabilities and Their Experiences of Harassment, Abuse and Related Crime in the Community. Lemos \& Crane: London.

Hemmings, C., Deb, S., Chaplin, E., Hardy, S., \& Mukherjee, R. (2013). Review of research for people With ID and mental health problems: A view from the United Kingdom. Journal of Mental Health Research in Intellectual Disabilities, 6(2), 127-158.

Home Office, Ministry of Justice, Office for National Statistics. (2013). An Overview of Hate Crime in England and Wales. London: Home Office.

Howlin, P., Goode, S., Hutton, J., Rutter, M. (2004) Adult outcome for children with autism. Journal of Child Psychology Psychiatry, 45 (2), 212- 229.

Hughes, K., Bellis, M. A., Jones, L., Wood, S., McCoy, E., Eckley, L., Bates, G., Mikton, C., Shakespeare, T \& Officer, A. (2012). Prevalence and risk of violence against adults with disabilities: a systematic review and meta-analysis of observational studies. The Lancet, 379 (9826), 1621-1629.

Iganski, P. (2008). 'Hate Crime' and the City. The Policy Press; Bristol. Joint Disability Hate Crime Review, 2013

King, C., \& Murphy, G. H. (2014). A Systematic Review of People with Autism Spectrum Disorder and the Criminal Justice System. Journal of autism and developmental disorders, 117.

Knapp, M., Romeo, R., Beecham, J. (2007). Economic Consequences of Autism in the UK. Mental Health Foundation and Autism Speaks. London, England Krug, E.G., Dahlberg, L.L., Mercy, J.A., Zwi, A.B., Lozano, R. (2002). World report on violence and health. World Health Organization, Geneva. 


\author{
MacPherson W. "The Inquiry Into The Matters Arising From The Death of Stephen Lawrence" \\ Mac Pherson Report: 24 February, 1999. \\ https://www.gov.uk/government/uploads/system/uploads/attachment data/file/277111/4 \\ 262.pdf
}

\author{
National Autistc Society 2010 \\ Nosek, M. A., Foley, C.C., Hughes, R.B., CA Howland, C.A. (2001). Vulnerabilities for abuse \\ among women with disabilities. Sex Disability, 19, 177-190. \\ Perry, B. (2001). In the Name of Hate: Understanding Hate Crimes. Routledge; London. \\ Quarmby, K. (2011). Scapegoat: why we are failing disabled people. Portobello Books, \\ London. \\ Roulstone, A. Thomas, P. \& Balderston, S. (2011) Between hate and vulnerability: unpacking \\ the British criminal justice system's construction of disablist hate crime. Disability and \\ Society, 26 (3), \\ Saxton, M., Curry, M.A., Powers, L.E., Maley, S., Eckels, K., Gross, J. (2001). 'Bring my scooter \\ so I can leave you'. A study of disabled women handling abuse by personal assistance \\ providers. Violence Against Women, 7, 393-417.
}

